\title{
FACTORS AFFECTING SELF-CARE ABILITY AMONG CHILDREN WITH MENTAL RETARDATION
}

\author{
Indanah \\ Nursing Program, School of Health Sciences Muhammadiyah Kudus
}

\begin{abstract}
Background: Mental retardation is a developmental problem manifested during a child's years of development (i.e. $0-18$ years old). It is a condition whereby a child's intelligence and adaptability are significantly below the average level of his peers.Self-care such as skills to dress and undress, look after oneself, use a toilet, take food independently, bathe, wash, is an important step on the way to their socialization. This study aimed to assess the effects of child and parental factors on self-care ability among children with mental retardation.

Subjects and Method: This was cross sectional study conducted at SDLB (special education for children with special needs), Kudus, Central Java. A sample of 132 children with mental retardation was selected for this study. The dependent variable was self-care ability. The independent variables were child age, maternal education, and parental support. The data were collected by questionnaire and analyzed by chi square with odd ratio (OR) as the measure of effect.

Results: Self-care ability of children with mental retardation increased with child age $(\mathrm{OR}=2.21 ; \mathrm{p}=0.037)$, higher maternal education $(\mathrm{OR}=3.50 ; \mathrm{p}=0.028)$, and strong parental support $(\mathrm{OR}=4.27 ; \mathrm{p}=0.001)$.

Conclusion: Self-care ability of children with mental retardation is positively associated with child age, maternal education, and parental support.
\end{abstract}

Keywords: mental retardation, self-care ability, child, parental factor.

\section{Correspondence:}

Indanah. Nursing Program, School of Health Sciences Muhammadiyah, Kudus, Central Java. Email: Indanah@stikesmuhkudus.ac.id. Mobile: 08157612666. 